\title{
A LITERATURE REVIEW ON ORAL HYPOGLYCEMIC DRUGS - MECHANISTIC ASPECTS
}

\author{
SYED WAJID ${ }^{1 *}$, MENAKA ${ }^{1}{ }^{1}$, FAZIL AHMED ${ }^{2}$, SANA SAMREEN ${ }^{3}$
}

${ }^{1}$ Department of Pharmacy, Annamalai University, Chidambaram, Tamil Nadu, India. ${ }^{2}$ Department of Pharmacy, Nizam Institute of Pharmacy Deshmukhi, Nalgonda, Telangana, India. ${ }^{3}$ Department of Pharmacy, Aurobindo College of Pharmaceutical Sciences, Warangal, Telangana, India. Email: wajidalisyed06@gmail.com

Received: 25 August 2019, Revised and Accepted: 01 October 2019

\begin{abstract}
Diabetes mellitus (DM) is a worldwide rising concern that leads to an increased rate of morbidity, mortality, and health-care costs. DM is a chronic, endocrine disorder associated with hyperglycemia. The current estimated DM prevalence is over 422 million and has been progressively increasing over the past decades. Consequently, it is considered a significant problem in health-care settings. Health-care professionals who deal with such patients need to have an adequate information and drug therapy management including drugs and its regimen that are presently available in the market. This review provides an overview of potential diabetic drugs and their mechanisms. Hence, it will be proved beneficial for health-care professionals.
\end{abstract}

Keywords: Diabetes, Clinical management, Metformin, Drugs, Sulfonylureas.

(c) 2019 The Authors. Published by Innovare Academic Sciences Pvt Ltd. This is an open access article under the CC BY license (http://creativecommons. org/licenses/by/4. 0/) DOI: http://dx.doi.org/10.22159/ajpcr.2019.v12i11.35469

\section{INTRODUCTION}

The prevalence of insulin and non-insulin-dependent diabetes has been largely raising over the past several decades [1]. Diabetes mellitus (DM) is a complex, chronic disease, yet it is treatable. DM currently affects over 422 million individuals and resulting in increased morbidity, mortality, and health-care costs [2,3]. Previous reports estimated that the number of diabetic patients will reach 552 million by 2030 [3]. DM is associated with problems related to cardiovascular, neurological, and kidneys besides other complications [4], and results in hospitalizations; therefore, effective management planning is of utmost importance [5].

DM is characterized by disruption of the system functioning and active metabolism, due to the lack of insulin or a combination of resistance to insulin and inadequate hormone secretion [6,7]. Type 1 diabetes arises from pancreatic islet B cell destruction, as a result of an autoimmune process, and these patients are relatively more prone to ketoacidosis. Formerly type 1 DM was known as juvenile diabetes for being more common in children and young adults [7,8]. Meanwhile, type 2 diabetes is the most prevalent form and results from insulin resistance with a defect in compensatory insulin secretion. DM is a serious complication that affects multiple systems in the human body and may result in premature death [6-8].

The diagnosis of DM is different from other diseases/conditions and confirmed according to one of the four criteria. Criteria number one involves random blood sugar of $200 \mathrm{mg}$ per deciliter or higher. While criteria two consider fasting blood sugar $<100 \mathrm{mg} / \mathrm{dL}$ or $5.6 \mathrm{mmol} / \mathrm{L}$, a patient with fasting blood sugar from 100 to $125 \mathrm{mg} / \mathrm{dL}$ is considered prediabetes. However, levels of $126 \mathrm{mg} / \mathrm{dL}$ or $7 \mathrm{mmol} / \mathrm{L}$ or even higher on two separate tests, indicates diabetes. The third criteria consist of sugar levels $>200 \mathrm{mg} / \mathrm{dL}$ after a $2 \mathrm{~h}$, 75-g oral glucose tolerance test, and the last criteria involve levels of hemoglobin A1C (HbA1c) $>6.5 \%$ [9]. American Diabetes Association recommends not to choose one test over another one for analysis of the results. Furthermore, it recommends to test all adults beginning at the age of 45 years, irrespective of weight and personality, and to test the conditions of individuals of any age who are overweight or obese, who present a diagnostic symptom, and have at least an additional risk factor for the development of diabetes [9]. The main aim of this study is to outline mechanisms of some antidiabetics drugs used for the treatment of diabetes, with the hope that this information can be further explored with modern scientific validation approaches to reveal new therapeutic leads for the treatment of diabetes.

\section{MATERIALS AND METHODS}

Source of information and search strategy for identifying relevant studies

To ensure a comprehensive research review of the subject, we performed searches using terms such as medical subject headings (MeSH) and key text words, such as "diabetics," "drugs," "mechanism of action" or "hypoglycemic drugs." Thus, the abstracts of published studies with relevant information on the mechanisms, pharmacokinetics, and dynamics of drugs to control diabetes were identified. These terms were used individually and in combination to ensure an extensive literature search. Relevant articles were selected and collated based on the broader objective of the review. This was achieved by searching databases, including PubMed, Google Scholar, SCOPUS, Web of Science, and Embase. From this common methodology discoveries and findings were identified and summarized in this final review. The most common symptoms associated with DM are shown in Fig. 1.

\section{ORAL HYPOGLYCEMIC DRUGS}

Sulfonylureas (such as gliclazide, gliclazide, glimepiride, and glyburide)

Sulfonylureas were discovered decades ago by Janbon et al. [10], who noticed their ability to control type 2 DM (T2DM) [11]. The basic mechanism of sulfonylureas involves the stimulation of the pancreatic islet beta-cells to secrete insulin. These drugs bind the adenosine triphosphate (ATP) sensitive potassium channels ( $\mathrm{H}+\mathrm{ATP}$ ) on the cell membrane of pancreatic beta cells, which depolarizes the cell by preventing $\mathrm{K}+$ from exiting and thus leads to the opening of voltage-gated $\mathrm{Ca}^{2+}$ channels. The increase in intracellular $\mathrm{Ca}^{2+}$ leads to increased fusion of insulin granules with the cell membrane, and therefore, augmented secretion of mature insulin $[11,12]$. This effect results in amplified responsiveness of $\beta$-cells to both glucose and non-glucose secretagogues, resulting in more insulin being released and lower blood glucose concentrations. Due to their mechanisms of action, studies have warned its use in patients with acute myocardial infarction $[11,12]$. 


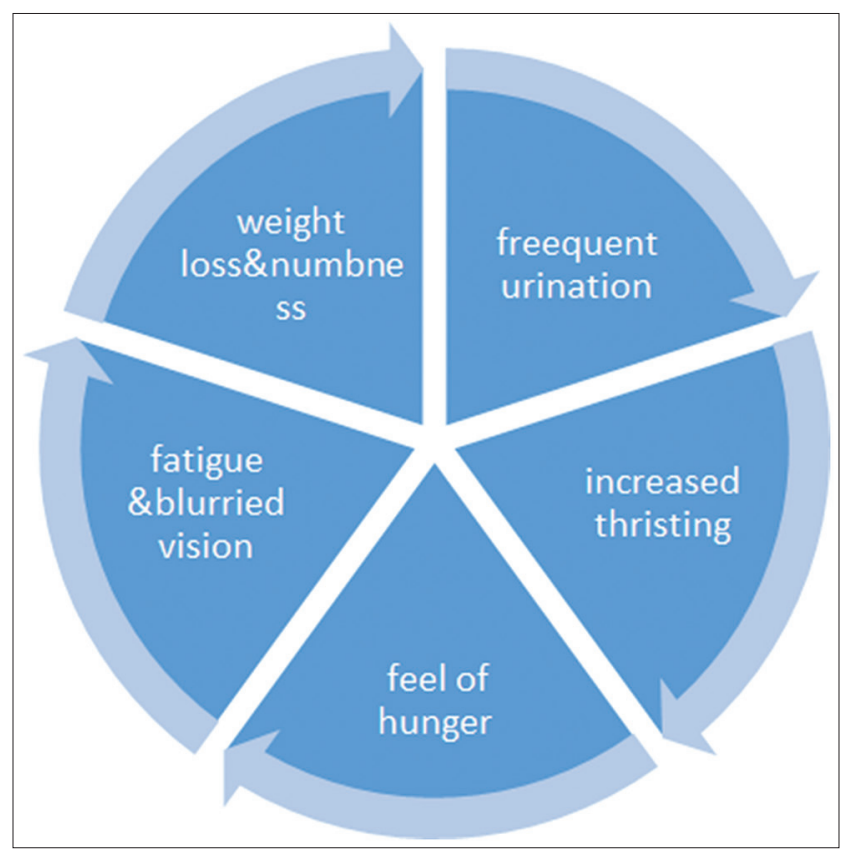

Fig. 1: The major symptoms of diabetes mellitus

Even though sulfonylureas and modified aryl sulfonylureas, which have substitutions at the two ends of the molecule, are products of sulfonamides, they do not have no inherent antibacterial activity. Depending on the potency of the sulfonylureas, they are classified as first-or second-generation agents. First-generation drugs include acetohexamide, chlorpropamide, tolbutamide, and tolazamide. The use of drugs from this class is not currently recommended due to their potential to elicit adverse effects, although these drugs are still available in the United States $[13,14]$. However, the second-generation, such as glipizide, gliclazide, and glibenclamide, known as glyburide and glimepiride, is the most commonly used internationally [14]. Further more a detailed information about the classes of diabetes drugs and their brand names were given in Table 1 .

All molecules belong to sulfonylurea share similar structural properties. However, second-generation sulfonylureas prescribed in lower doses and are administered once daily due to their high potency rate and have been found as the first choice in management of type 2 diabetes. Importantly, more benefits and better results have been reported when these drugs were administered with adequate diet and lifestyle changes $[15,16]$. The pharmacokinetics of sulfonylureas were clearly documented in many reports to be well absorbed after oral administration, and with peak plasma concentrations at $2-4 \mathrm{~h}[11,17]$.

Glyburide, also commonly known as glibenclamide, remains the most popular drug with the brand name of Diabeta and Micronase, and it is available in doses of $1.25,2.5$, and $5 \mathrm{mg}$. Gliclazide generic drugs with the brand names of Diamicron and Dianorm are available in several countries. Both drugs glyburide and gliclazide have duration of action for up to $12-24 \mathrm{~h}$ regarded as an intermediate-acting drug and eliminated through liver and kidney, respectively [18-20].

Similarly, the drug glimepiride, which is very popular with the brand name of Amaryl, is available in doses of 1-4 mg. Combined and fixed doses of glimepiride and thiazolidinediones (TZDs) have also been marketed (with rosiglitazone as Avandaryl, and pioglitazone as Duetact). The reported duration of action for glimepiride was longer than $24 \mathrm{~h}$ and mainly eliminated through the liver [21]. Another drug called glipizide, also available in the market with the common trade name of Glucotrol, has doses of 5 and $10 \mathrm{mg}$. It is also available in an extended-release form (Glucotrol XL) of 2.5, 5, and $10 \mathrm{mg}$. Higher concentrations of the drug should be given in divided doses throughout the day and to a maximum of $40 \mathrm{mg}$. Fixed combinations of glipizide with metformin are also available in both generic and brand name forms (Metaglip). One of the major drawbacks of sulfonylureas is that they have a high affinity to bind plasma proteins.

Sulfonylureas were reported effective in patients unresponsive to nonpharmacological treatments and non-obese patients. They can be administered as single or combined drugs to provide a longer effect and depending on the treatment regimen, for example, a day time dose of sulfonylureas and night time dose of insulin regimen [22]. The effectiveness of mixed combinations mainly depends on which drug is used. However, with the addition of metformin or any TZD derivative, a maximum reduction of $1 \%$ in HbA1c levels can be achieved [23]. These classes of drugs are mainly contraindicated to patients with type $1 \mathrm{DM}$, and during pregnancy, and in the presence of renal and liver diseases [19,24].

The main side effects reported for this category of medicines were hypoglycemia, increased weight, allergic skin reactions, acute porphyria, rarely, and hyponatremia [22,25,26].

\section{Repaglinide, nateglinide}

Repaglinide, most commonly available with the name of Prandin, and nateglinide, called with the name of Starlix, are short-acting substances which promote the secretion of insulin and were recently approved for the management of type 2 diabetes [27-29]. These drugs are shortly effective before meals in the stimulation of rapid release of insulin. The mechanism of these classes of drugs was related to the that of sulfonylureas; repaglinide and nateglinide exert their efficacy by inhibiting ATP-sensitive potassium channels (KATP channel) in pancreatic $\beta$-cells, thus inducing depolarization of $\beta$-cell membranes and inflow of $\mathrm{Ca} 2+$ ions into the cells to stimulate insulin secretion [30-32].

Repaglinide, rapidly absorbed after meals, produces peaks of insulin concentrations within $1 \mathrm{~h}(\mathrm{t} t / 2=0.6 \mathrm{~h})$. It is metabolized in the liver and excreted mainly through the fecal matter and urine. Nateglinide has $\mathrm{t} 1 / 2=1.5 \mathrm{~h}$ and a period of action of 5-6 $\mathrm{h}$. In comparison to repaglinide, this drug has active metabolites. Excretion of nateglinide is mainly through the bile and urine [33,34]. Earlier published results of clinical trials have established that both agents increase insulin response to postprandial glucose, resulting in reductions of HbA1c and fasting plasma glucose (FPG) levels [28]. 
Table 1: The classes of diabetes drugs and their brand names

\begin{tabular}{|c|c|}
\hline Class of drug & (Generic) brand name \\
\hline Sulfonylureas & $\begin{array}{l}\text { Gliclazide } \\
\text { Gliclazide } \\
\text { Glimepiride } \\
\text { Glyburide }\end{array}$ \\
\hline Rapid-acting prandial insulin releasers & $\begin{array}{l}\text { Prandin } \\
\text { nateglinide }\end{array}$ \\
\hline Biguanides & $\begin{array}{l}\text { Metformin } \\
\text { Metformin extended-release }\end{array}$ \\
\hline Thiazolidinediones & $\begin{array}{l}\text { Pioglitazone, } \\
\text { Rosiglitazone }\end{array}$ \\
\hline Alpha-glucosidases inhibitor & Acarbose (Glucobay) \\
\hline Dipeptidyl-peptidase-4 (DPP-4) inhibitors & Linagliptin (Trajenta), Saxagliptin (Onglyza MC), Sitagliptin (Januvia), Alogliptin (Nesina) \\
\hline Glucagon-like peptide-1 (GLP-1) agonist & $\begin{array}{l}\text { Exenatide } \\
\text { Exenatide extended-release } \\
\text { Liraglutide } \\
\text { Dulaglutide } \\
\text { Lixisenatide } \\
\text { Semaglutide }\end{array}$ \\
\hline Sodium glucose cotransporter 2 (SGLT2) inhibitors & $\begin{array}{l}\text { Canagliflozin (Invokana) } \\
\text { Dapagliflozin (Forxiga) Empagliflozin (Jardiance) } \\
\text { Ertugliflozin (Steglatro TM) }\end{array}$ \\
\hline
\end{tabular}

Repaglinide is useful for patients who have difficulties in achieving glycemic control with the diet, or due to their lifestyle, or an improper lifestyle, which results in missed or random meals during the day. Unlike sulfonylureas, these drugs have a lower risk of hypoglycemia and weight gain; hence, it is a common choice for elderly patients [35-37].

\section{Biguanides (metformin, metformin extended-release)}

The use and popularity of biguanides were well documented in previous reports. Over decades ago, the use of biguanides has increased around the world, and they are considered as first-line drugs in the management of T2DM irrespective of age $[8,38]$. The primary function of metformin is to decrease the blood glucose concentration in patients with T2DM, mainly in those overweight, and also in those patients whose kidneys function normally [39]. Previous reports revealed that they are safe and effective as monotherapy and in combination with other oral antidiabetic agents and insulin [39].

The drug metformin acts by lowering both hyperglycemia and hyperinsulinemia, which ultimately increase glucose tolerance in patients with T2DM [40]. Its mechanism of action differs from other classes of oral antihyperglycemic agents. Metformin acts on the liver by decreasing hepatic glucose production; it also decreases intestinal absorption of glucose and improves insulin sensitivity by increasing peripheral glucose uptake and consumption [14]. In conjunction with sulfonylureas, the drug metformin does not yield hypoglycemia in either patient with T2DM or normal subjects and does not cause hyperinsulinemia [39-41].

Metformin decreases HbA1c and FPG levels by approximately 1.5-2.0\% and $50-70 \mathrm{mg} / \mathrm{dL}$, respectively [14,41]. The half-life of metformin is $5 \mathrm{~h}$ after oral absorption, and the drug is mainly excreted through the kidneys. Metformin is contraindicated to patients who have advanced stages of renal insufficiency [42]. The commonly reported side effects of metformin were gastrointestinal disturbances, including upset stomach, a metallic taste in the mouth, mild anorexia, nausea, and abdominal discomfort, lactic acidosis, especially in patients with renal insufficiency, and soft bowel movements or diarrhea [41]. Several studies also reported that the use of metformin altered the levels of methylcobalamin and folic acid, particularly in individuals with metformin intolerance [43].

TZDs (pioglitazone, rosiglitazone)

TZD was introduced in early 1997. They have a strong immunostimulatory effect, along with the property, to relieve or prevent arthritic symptoms and oncostatic activity [44]. Other studies reported antidiabetic, anti-inflammatory [45], and in vivo and in vitro anti-cancerogenic effects of these drugs, including in colon, breast, and prostate $[46,47]$.

TZD decreases abnormally high blood glucose levels by improving insulin sensitivity. Rosiglitazone and pioglitazone are the only two drugs in this class presently accessible in the United States. TZD acts by binding to the nuclear paroxysmal proliferator-activated receptor, subsequently activating genes that encode for proteins involved in the glucose and lipid metabolisms. This interaction leads to a rise in glucose uptake by the skeletal muscle and adipose tissue, a reduction in hepatic glucose output, and finally, an increase in free fatty acid uptake, which in conjunction results in the decrease of glucose and HbA1c levels over the time. Previous data reported that TZD provided lasting glycemic control in diabetes patients $[11,48]$

TZD can be used in both obese and non-obese patients when other treatment options failed. Monotherapy with rosiglitazone has been shown to decrease HbA1c levels by $1.2 \%-1.5 \%$, compared to placebo after 26 weeks of therapy [49]. Similarly, another study reported a reduction of $\mathrm{HbA} 1 \mathrm{c}$ levels by $\pm 0.5-1.5 \%$ [11]. In addition, the combination of TZD with metformin and sulfonylureas was considered safe. However, administration of TZD with insulin was prohibited and it is contraindicated in patients with acute liver disease due to its hepatotoxicity risk [11].

The most common reported side effects of TZD administration include increased weight (about 1-4 kg over 6-12 months), edema with worsening of cardiac failure, liver toxicity, and anemia [50].

\section{Alpha-glucosidase inhibitors}

Acarbose was the first glucosidase inhibitor discovered in early 1990 [11]. Acarbose is an oral antidiabetic drug used for treating T2DM and functions by preventing the digestion of starch and table sugar. The carbohydrates are normally converted into simple sugars by the alpha-glucosidase enzymes present in the cells lining the intestine. These alpha-glucosidases hydrolyze oligosaccharides, trisaccharides, and disaccharides to glucose and other monosaccharides in the small intestine [11,51], thus facilitating absorption of monosaccharides through the intestine. However, alpha-glucosidase inhibitors, such as acarbose, competitively inhibit enzymes necessary to digest carbohydrates, specifically alpha-glucosidase enzymes in the small intestines. 
Previous studies reported that alpha-glucosidase inhibitors also block pancreatic alpha-amylase, which is known to hydrolyze complex carbohydrates into oligosaccharides in the lumen of the small intestine. Inhibition of these enzyme systems reduces the rate of digestion of carbohydrates, which results in reduced absorption of glucose because the carbohydrates are not broken down into glucose molecules. However, the short-term effect of these drugs on diabetic patients is to decrease current blood glucose levels, while the long-term effect is to minimally reduce HbA1c levels [11,52].

After the oral administration of the drug, only $<2 \%$ of the drug is absorbed. This process occurs through the intestinal amylases and certain intestinal bacteria. The rest of the drug is excreted through urine. The drug should be taken during a meal [11]. The use of acarbose is prohibited during pregnancy and breastfeeding, and the reported side effects included flatulence, abdominal discomfort, and diarrhea. However, tolerance to the side effects quickly develops. The reported incidence of hypoglycemia can occur when used in combination with sulfonylureas or insulin drugs and products [11]

\section{Dipeptidyl-peptidase-4 (DPP-4) inhibitors}

DPP-4 inhibitors are a class of antidiabetic drugs used for the pharmacological management of T2DM. The most common drugs are sitagliptin, saxagliptin, vildagliptin, linagliptin, teneligliptin, and alogliptin.

DPP-4 mainly works by blocking the enzyme DPP-4. In 2006, the first DPP-4 inhibitor, sitagliptin, was introduced by Merck pharmaceuticals with the brand name of Januvia and approved by the U.S. Food and Drug Administration (FDA). This class of drugs represents a novel treatment of diabetes and may be combined with current modalities to improve glycemic control $[53,54]$.

The major of action of DPP-4 inhibitors is to reduce glucagon and blood glucose levels, by rising incretin levels, such as glucagon-like peptide-1 (GLP-1) and glucose-dependent insulinotropic polypeptide (GIP), which prevent glucagon release. Thus, reducing glucagon release increases the secretion of insulin, reduces gastric emptying, and decreases blood glucose levels $[55,56]$. A recent meta-analysis report revealed no favorable effect of DPP-4 inhibitors on all-cause mortality, cardiovascular mortality, myocardial infarction, or stroke [57]

The most commonly reported that adverse effects were nasopharyngitis, headache, nausea, heart failure [56], acute pancreatitis [58], ulcerative colitis [59], and hypersensitivity to skin reactions. The FDA has issued a warning, which was added to the labels of all medicines in this drug class such as sitagliptin and saxagliptin that they may cause severe and disabling joint pain [60]. However, there was not enough evidence which reveals the risk of rheumatoid arthritis among users of DPP-4 inhibitors [61].

\section{GLP-1 agonist}

GLP-1 as well as GIP are secreted by the small intestine in response to food intake. These hormones stimulate insulin secretion, insulin gene expression, and pancreatic beta-cell growth. In addition, they mediate the incretin effect, which increases insulin secretion subsequent to oral administration of glucose. The GLP-1 molecule is subjected to enzymatic degradation by the DPP-4 (dipeptidyl peptidase) enzyme [11]

The GLP-1 agonists, exenatide, liraglutide, lixisenatide, albiglutide (known as Tanzeum), dulaglutide, and semaglutide were approved in 2005-2012, 2010, 2016, 2014, 2015 [9], and 2017 [52], respectively. The patients who recently were diagnosed with T2DM along with an unbalanced metabolic profile could benefit more from GLP-1 analogs as they stimulate weight loss and improve metabolic dysfunction.

\section{Exendin-4 (exenatide)}

Exendin-4, approved in April 2005, belongs to the group of incretin mimetics. This drug was initially isolated from the venom of the Gila monster and has a synthetic version named exenatide. The route of administration is subcutaneously, particularly under the skin of the abdomen, thigh, or arm and should be performed at any time within the $60 \mathrm{~min}$ before the first and last meal of the day [52].

Exenatide is used to treat T2DM as a combination with metformin, biguanide, or a combination of metformin and a sulfonylurea, or TZD, such as pioglitazone $[62,63]$. The most common reported side effects of exenatide use were acid or sour stomach, belching, diarrhea, heartburn, indigestion, nausea, and vomiting; therefore, exenatide should not be used by people with severe gastrointestinal disease. Other side effects include dizziness and headache [64]

\section{Sodium glucose cotransporter 2 (SGLT2) inhibitors}

SGLT2 inhibitors are a novel class of FDA-approved medications that have been recently available as monotherapy or in conjunction with other hypoglycemic drugs, including metformin [65]. When these drugs, including canagliflozin, dapagliflozin, and empagliflozin, are combined with healthy food and adequate physical workout, they suppress blood sugar levels in elderly patients with T2DM.

The main mechanism of SGLT2 inhibitors' action is to signal the kidney to eliminate the excess of sugar through the urine. Since their mechanism is glucose-independent; hence, they could be effective in advanced stages of T2DM when pancreatic $\beta$-cell reserves are permanently lost. This class of drugs also stimulates weight loss along with reduction of the blood pressure $[6,65]$. Previous studies reported that the main adverse effects associated with their use were urinary tract infections, pyelonephritis, and genital mycosis $[8,65]$.

\section{CONCLUSION}

DM is one of the leading causes of several chronic diseases, including renal complications. The disease predominantly affects individuals of all ages irrespective of gender. As the number of patients with DM increases every day, it is becoming a challenge for health-care professionals to treat them. Hence, good knowledge and understanding of the available treatment modalities is of great value.

\section{AUTHORS' CONTRIBUTIONS}

SW has compiled the whole manuscript, has generated the idea, and MM and FA both provided necessary guidance while compilation, and, SS, helped in routine check while drafting the manuscript .

\section{CONFLICTS OF INTEREST STATEMENT}

The authors declared that they have no conflicts of interest.

\section{REFERENCES}

1. Harris MI, Flegal KM, Cowie CC, Eberhardt MS, Goldstein DE, Little RR, et al. Prevalence of diabetes, impaired fasting glucose, and impaired glucose tolerance in U.S. Adults. The third national health and nutrition examination survey, 1988-1994. Diabetes Care 1998;21:518-24.

2. World Health Organization; Global Report on Diabetes. Available from: http://www.who.int/diabetes/global-report/en.

3. Whiting DR, Guariguata L, Weil C, Shaw J. IDF diabetes atlas: Global estimates of the prevalence of diabetes for 2011 and 2030. Diabetes Res Clin Pract 2011;94:311-21.

4. Wang Y, Yeo QQ, Ko Y. Economic evaluations of pharmacist-managed services in people with diabetes mellitus: A systematic review. Diabet Med 2016;33:421-7.

5. Inzucchi SE, Bergenstal RM, Buse JB, Diamant M, Ferrannini E, Nauck M, et al. Management of hyperglycaemia in Type 2 diabetes: A patient-centered approach. Position statement of the American diabetes association (ADA) and the European association for the study of diabetes (EASD). Diabetologia 2012;55:1577-96.

6. Standards of medical care in diabetes-2016: Summary of revisions. Diabetes Care 2016;39 Suppl 1:S4-5.

7. Mayo Clinic Diabetes. Available from: https://www.mayoclinic.org/ diseases-conditions/diabetes/diagnosis-treatment/drc-20371451.

8. Chaudhury A, Duvoor C, Reddy Dendi VS, Kraleti S, Chada A, 
Ravilla R, et al. Clinical review of antidiabetic drugs: Implications for Type 2 diabetes mellitus management. Front Endocrinol (Lausanne) 2017;8:6.

9. American Diabetes Association. (2) classification and diagnosis of diabetes. Diabetes Care 2015;38 Suppl 1:S8-16.

10. Janbon M, Chaptal J, Vedel A, Schaap J. Accidents hypoglycémiques graves par un sulfamidothiodiazol (le VK 57 ou 2254 RP). Montp Med 1942;441:21-2.

11. Bösenberg LH, van Zyl DG. The mechanism of action of oral antidiabetic drugs: A review of recent literature. J Endocrinol Metab Diabetes South Afr 2008;13:80-8.

12. Proks P, Reimann F, Green N, Gribble F, Ashcroft F. Sulfonylurea stimulation of insulin secretion. Diabetes 2002;51 Suppl 3:S368-76.

13. Aguilar-Bryan L, Nichols CG, Wechsler SW, Clement JP $4^{\text {th }}$, Boyd AE $3^{\text {rd }}$, González G, et al. Cloning of the beta cell high-affinity sulfonylurea receptor: A regulator of insulin secretion. Science 1995;268:423-6.

14. Lorenzati B, Zucco C, Miglietta S, Lamberti F, Bruno G. Oral hypoglycemic drugs: Pathophysiological basis of their mechanism of actionOral hypoglycemic drugs: Pathophysiological basis of their mechanism of action. Pharmaceuticals (Basel) 2010;3:3005-20

15. Drugs for Type 2 diabetes. Med Lett Drugs Ther 2017;59:9-18.

16. Inzucchi SE. Oral antihyperglycemic therapy for Type 2 diabetes: Scientific review. JAMA 2002;287:360-72.

17. Bressler R, Johnson DG. Pharmacological regulation of blood glucose levels in non-insulin-dependent diabetes mellitus. Arch Intern Med 1997; $157: 836-48$

18. Jönsson A, Rydberg T, Ekberg G, Hallengren B, Melander A. Slow elimination of glyburide in NIDDM subjects. Diabetes Care 1994; $17: 142-5$.

19. Jönsson A, Rydberg T, Sterner G, Melander A. Pharmacokinetics of glibenclamide and its metabolites in diabetic patients with impaired renal function. Eur J Clin Pharmacol 1998;53:429-35.

20. Tessier D, Dawson K, Tétrault JP, Bravo G, Meneilly GS. Glibenclamide vs gliclazide in Type 2 diabetes of the elderly. Diabet Med 1994;11:974-80.

21. Langtry HD, Balfour JA. Glimepiride. A review of its use in the management of Type 2 diabetes mellitus. Drugs 1998;55:563-84.

22. DeFronzo RA. Pharmacologic therapy for Type 2 diabetes mellitus. Ann Intern Med 2000;133:73-4.

23. Monami M, Lamanna C, Marchionni N, Mannucci E. Comparison of different drugs as add-on treatments to metformin in Type 2 diabetes: A meta-analysis. Diabetes Res Clin Pract 2008;79:196-203.

24. Shorr RI, Ray WA, Daugherty JR, Griffin MR. Incidence and risk factors for serious hypoglycemia in older persons using insulin or sulfonylureas. Arch Intern Med 1997;157:1681-6.

25. Chounta A, Zouridakis S, Ellinas C, Tsiodras S, Zoumpouli C, Kopanakis $\mathrm{S}$, et al. Cholestatic liver injury after glimepiride therapy. J Hepatol 2005;42:944-6.

26. Garratt KN, Brady PA, Hassinger NL, Grill DE, Terzic A, Holmes DR Jr., et al. Sulfonylurea drugs increase early mortality in patients with diabetes mellitus after direct angioplasty for acute myocardial infarction. J Am Coll Cardiol 1999;33:119-24

27. Rosenstock J, Hassman DR, Madder RD, Brazinsky SA, Farrell J, Khutoryansky N, et al. Repaglinide versus nateglinide monotherapy: A randomized, multicenter study. Diabetes Care 2004;27:1265-70

28. Novo Nordisk Pharmaceuticals: Repaglinide Product Labeling; 2003. Available from: https://www.accessdata.fda.gov/drugsatfda docs/ label/2012/020741s0401bl.pdf. [Last accessed on 2019 Oct 27].

29. Raskin P, Klaff L, McGill J, South SA, Hollander P, Khutoryansky N, et al. Efficacy and safety of combination therapy: Repaglinide plus metformin versus nateglinide plus metformin. Diabetes Care 2003;26:2063-8

30. Gromada J, Dissing S, Kofod H, Frøkjaer-Jensen J. Effects of the hypoglycaemic drugs repaglinide and glibenclamide on ATP-sensitive potassium-channels and cytosolic calcium levels in beta TC3 cells and rat pancreatic beta cells. Diabetologia 1995;38:1025-32

31. Fuhlendorff J, Rorsman P, Kofod H, Brand CL, Rolin B, MacKay P, et al. Stimulation of insulin release by repaglinide and glibenclamide involves both common and distinct processes. Diabetes 1998;47:345-51.

32. Hansen AM, Christensen IT, Hansen JB, Carr RD, Ashcroft FM, Wahl P, et al. Differential interactions of nateglinide and repaglinide on the human beta-cell sulphonylurea receptor 1. Diabetes 2002;51:2789-95.

33. Culy CR, Jarvis B. Repaglinide: A review of its therapeutic use in Type 2 diabetes mellitus. Drugs 2001;61:1625-60.

34. Dunn CJ, Faulds D. Nateglinide. Drugs 2000;60:607-15.

35. Gribble FM, Manley SE, Levy JC. Randomized dose ranging study of the reduction of fasting and postprandial glucose in Type 2 diabetes by nateglinide (A-4166). Diabetes Care 2001;24:1221-5.

36. Moses RG, Gomis R, Frandsen KB, Schlienger JL, Dedov I. Flexible meal-related dosing with repaglinide facilitates glycemic control in therapy-naive Type 2 diabetes. Diabetes Care 2001;24:11-5.

37. Guardado-Mendoza R, Prioletta A, Jiménez-Ceja LM, Sosale A, Folli F. The role of nateglinide and repaglinide, derivatives of meglitinide, in the treatment of Type 2 diabetes mellitus. Arch Med Sci 2013;9:936-43.

38. Bailey CJ, Turner RC. Metformin. N Engl J Med 1996;334:574-9.

39. Song R. Mechanism of metformin: A tale of two sites. Diabetes Care 2016;39:187-9

40. Pollak M. Metformin and other biguanides in oncology: Advancing the research agenda. Cancer Prev Res (Phila) 2010;3:1060-5

41. DeFronzo RA, Goodman AM. Efficacy of metformin in patients with non-insulin-dependent diabetes mellitus. The multicenter metformin study group. N Engl J Med 1995;333:541-9.

42. Johansen K. Efficacy of metformin in the treatment of NIDDM. Meta-analysis. Diabetes Care 1999;22:33-7.

43. Fogelman Y, Kitai E, Blumberg G, Golan-Cohen A, Rapoport M, Carmeli E, et al. Vitamin B12 screening in metformin-treated diabetics in primary care: Were elderly patients less likely to be tested? Aging Clin Exp Res 2017;29:135-9.

44. Moretti RM, Montagnani Marelli M, Motta M, Limonta P. Oncostatic activity of a thiazolidinedione derivative on human androgen-dependent prostate cancer cells. Int J Cancer 2001;92:733-7.

45. Kurebayashi S, Xu X, Ishii S, Shiraishi M, Kouhara H, Kasayama S, et al. A novel thiazolidinedione MCC-555 down-regulates tumor necrosis factor-alpha-induced expression of vascular cell adhesion molecule-1 in vascular endothelial cells. Atherosclerosis 2005;182:71-7.

46. Sarraf P, Mueller E, Jones D, King FJ, DeAngelo DJ, Partridge JB, et al. Differentiation and reversal of malignant changes in colon cancer through PPARgamma. Nat Med 1998;4:1046-52.

47. Elstner E, Müller C, Koshizuka K, Williamson EA, Park D, Asou H, et al. Ligands for peroxisome proliferator-activated receptorgamma and retinoic acid receptor inhibit growth and induce apoptosis of human breast cancer cells in vitro and in BNX mice. Proc Natl Acad Sci U S A 1998;95:8806-11.

48. Vasudevan AR, Balasubramanyam A. Thiazolidinediones: A review of their mechanisms of insulin sensitization, therapeutic potential, clinical efficacy, and tolerability. Diabetes Technol Ther 2004;6:850-63.

49. Olefsky JM, Saltiel AR. PPAR gamma and the treatment of insulin resistance. Trends Endocrinol Metab 2000;11:362-8.

50. Semple RK, Chatterjee VK, O'Rahilly S. PPAR gamma and human metabolic disease. J Clin Invest 2006;116:581-9.

51. Venable SJ, Aschenbrenner DS. Drug Therapy in Nursing. Hagerstown, MD: Lippincott Williams and Wilkins; 2005.

52. Food and Drug Administration. FDA Approves New Treatment for Diabetes (Press Release). Oxford: U.S. Food and Drug Administration; 2006.

53. Pathak R, Bridgeman MB. Dipeptidyl peptidase-4 (DPP-4) inhibitors in the management of diabetes. P T 2010;35:509-13.

54. McIntosh CH, Demuth HU, Pospisilik JA, Pederson R. Dipeptidyl peptidase IV inhibitors: How do they work as new antidiabetic agents? Regul Pept 2005;128:159-65

55. Behme MT, Dupré J, McDonald TJ. Glucagon-like peptide 1 improved glycemic control in Type 1 diabetes. BMC Endocr Disord 2003;3:3

56. Dupre J, Behme MT, Hramiak IM, McFarlane P, Williamson MP, Zabel $\mathrm{P}$, et al. Glucagon-like peptide I reduces postprandial glycemic excursions in IDDM. Diabetes 1995;44:626-30.

57. Zheng SL, Roddick AJ, Aghar-Jaffar R, Shun-Shin MJ, Francis D, Oliver N, et al. Association between use of sodium-glucose cotransporter 2 inhibitors, glucagon-like peptide 1 agonists, and dipeptidyl peptidase 4 inhibitors with all-cause mortality in patients with Type 2 diabetes: A Systematic review and meta-analysis. JAMA 2018;319:1580-91.

58. Diabetes Meds Containing Saxagliptin and Alogliptin Linked to Increased HF; 2016. Available from: https://www.pharmacypracticenews. com/Policy/Article/04-16/Diabetes-Meds-Containing-Saxagliptin-andAlogliptin-Linked-to-Increased-HF/35964/ses $=$ ogst

59. Abrahami D, Douros A, Yin $\mathrm{H}, \mathrm{Yu} \mathrm{OH}$, Renoux C, Bitton A, et al. Dipeptidyl peptidase-4 inhibitors and incidence of inflammatory bowel disease among patients with Type 2 diabetes: Population based cohort study. BMJ 2018;360:k872.

60. DPP-4 Inhibitors for Type 2 Diabetes: Drug Safety Communication-May Cause Severe Joint Pain. FDA; 2015. Available from: https://www. medscape.com/viewarticle/850231. [Last accessed on 2015 Sep 10]

61. Kathe N, Shah A, Said Q, Painter JT. DPP-4 inhibitor-induced 
rheumatoid arthritis among diabetics: A nested case-control study. Diabetes Ther 2018;9:141-51.

62. Byetta 10 Micrograms Solution for Injection, Prefilled Pen Summary of Product Characteristics. Electronic Medicines Compendium; 2017. Available from: https://www.medicines.org.uk/emc/product/8617/ smpc.

63. Bydureon $2 \mathrm{mg}$ Powder and Solvent for Prolonged-release Suspension for Injection in Pre-filled Pen Summary of Product Characteristics.
Electronic Medicines Compendium; 2017. Available from: https:// www.medicines.org.uk/emc/product $/ 3650 /$ smpc.

64. US Food Drug Administration. Sodium-glucose Cotransporter-2 (SGLT2) Inhibitors. Available from: https://www.fda.gov/Drugs/ DrugSafety/ucm446852.htm.

65. Riser Taylor S, Harris KB. The clinical efficacy and safety of sodium glucose cotransporter-2 inhibitors in adults with Type 2 diabetes mellitus. Pharmacotherapy 2013;33:984-99. 